\title{
Recombinant DNase in cystic fibrosis: a protocol for targeted introduction through n-of-1 trials
}

\author{
F.G.E. Böllert*, J.Y. Paton**, T.G. Marshall ${ }^{+}$, J. Calvert*, A.P. Greening*, J.A. Innes*, \\ on behalf of the Scottish Cystic Fibrosis Group
}

Recombinant DNase in cystic fibrosis: a protocol for targeted introduction through n-of-1 trials. F.G.E. Böllert, J.Y. Paton, T.G. Marshall, J. Calvert, A.P. Greening, J.A. Innes on behalf of the Scottish Cystic Fibrosis Group. (C)ERS Journals Ltd 1999

ABSTRACT: Nebulized recombinant human deoxyribonuclease (DNase) reduces sputum viscosity and improves lung function in some cystic fibrosis patients, but individual responses are unpredictable.

The aim of this study was to investigate how DNase can be targeted to those cystic fibrosis patients who would benefit most.

The Scottish Cystic Fibrosis Group agreed on a randomized, double-blind, placebocontrolled n-of-1 assessment protocol. Patients underwent a maximum of three 4-week assessment periods ( 2 weeks saline, 2 weeks DNase each). Measurements performed at hospital (exercise, oximetry and spirometry) and home (symptom scores) were used to derive a scoring system to discriminate maximally between DNase and placebo effects. The data on 89 4-week assessments in 52 patients were reported.

Twenty-four patients have completed the assessment process (12 responders and 12 nonresponders) to date. Forced expiratory volume in one second (FEV1) was the best discriminator of response, rising by $>200 \mathrm{~mL}$ after DNase in 33 of $89(37 \%)$ assessments compared with 3 of $89(3 \%)$ after saline.

$\mathrm{N}$-of-1 trials, while laborious, permitted genuine treatment effects to be quantified within individuals with confidence, permitting appropriate treatment targeting. This provides a model of how other new expensive therapies may be introduced to maximize patient benefit.

Eur Respir J 1999; 13: 107-113.
*Scottish Adult Cystic Fibrosis Service, Western General Hospital, Edinburgh, UK. **Royal Hospital for Sick Children, Glasgow, UK. ${ }^{+}$Royal Hospital for Sick Children, Edinburgh, UK.

\section{Correspondence: J.A. Innes}

Scottish Adult Cystic Fibrosis Service Respiratory Unit

Western General Hospital NHS Trust

Edinburgh EH4 2XU

UK

Fax: 441313433989

Keywords: Cystic fibrosis

DNase

n-of-1 trials

Received: September 41997

Accepted after revision August 151998

The authors acknowledge gratefully the financial assistance of Roche-Genentech for overlabelling, randomization and packaging cost.
In cystic fibrosis (CF), airway obstruction by viscid mucus leads to chronic endobronchial infection and ultimately to death from respiratory failure at a median age of 28 yrs [1-3]. The viscosity of CF sputum is in part due to deoxyribonucleic acid (DNA) released from dead neutrophils [4-6], and recombinant human deoxyribonuclease (DNase) reduces sputum viscosity in vitro [7]. Several phase II and III clinical trials [8-11] have demonstrated small average benefits in large study groups. The significant nonresponder rate and the lack of useful predictors of individual response in the published trials together with the resource implications of treatment $(£ 7,442$ a year for each patient on once daily dosing) raise the question of how best to identify that subset of patients who will derive most benefit from nebulized DNase.

One possible approach to this problem is to test for significant treatment effects within individuals using repeated measurements and a randomized, double-blind, placebo-controlled design. This method ("n-of-1 trial" [12]) allows patients to serve as their own controls and removes intersubject variability from the assessment data. The Scot- tish Cystic Fibrosis Group (comprising physicians and paediatricians caring for most Scottish CF patients) designed such an "n-of-1" assessment of the effects of once daily $(2.5 \mathrm{mg})$ nebulized DNase. The experience of its use in 52 patients attending seven CF centres in Scotland is reported.

\section{Materials and methods}

\section{Study subjects}

CF patients aged $>5$ yrs with a forced vital capacity (FVC) $>40 \%$ of predicted normal, with evidence of daily sputum production and in a stable clinical condition (no intravenous antibiotics for 2 weeks previously) were invited to participate. Verbal consent was obtained from the patient or guardian as appropriate. Since the intention was the directed use of a licensed preparation it was considered inappropriate to seek ethics committee approval.

\section{Study design}

Rationale. The n-of-1 assessment protocol was designed to be: 1) blinded and placebo controlled to minimize the

Additional contributing members of the Scottish Cystic Fibrosis Group: J.A.R. Friend, J.S. Legge (Adult Cystic Fibrosis Service, Aberdeen Royal Infirmary, Aberdeen, UK); J.D. Wilkinson (Royal Hospital for Sick Children, Glasgow, UK); B.H.R. Stack (West of Scotland Adult Cystic Fibrosis Centre, Gartnavel General Hospital, Glasgow, UK); G. Russell (Royal Aberdeen Children's Hospital, Aberdeen, UK); A. Mehta, J. Winter (Ninewells Hospital Medical School, Dundee, UK). 
influence of preconceived expectations on results; 2) based on clinically relevant outcomes, including objective measures of functional capacity and self-scored symptoms; 3) of a duration and complexity which could be managed within a typical CF clinic; and 4) reliable despite the natural variability in the clinical condition of $\mathrm{CF}$ patients over time.

Phase II trials [8, 9] have shown that DNase begins to affect pulmonary function within 5 days and that the majority of the effect disappears within 10 days of cessation of short-term treatment. An assessment protocol was therefore designed in which patients receive nebulized treatment for two consecutive 14-day periods, with placebo or DNase being randomly allocated to the first or second period. Thus, each assessment lasts 28 days, and is evaluated as showing a response or not (see below). To allow for the natural variability in clinical condition of patients, the 28-day assessments were repeated in each patient up to three times, until either two assessments showed a response or two showed no response (best of three assessments).

Measurements. The parameters measured in the protocol are those which were found in practice to change differently in response to placebo and DNase. Numerous other measurements (including weight, peak flow, white cell count and self-rated scores for ease of clearing sputum, wellbeing and appetite) were included in the pilot protocol but were discarded after analysis because they did not change differently in response to placebo and DNase.

Objective measures. At day 1, 14 and 28, i.e. before treatment and after each 14-day treatment period, the following measurements were recorded at a hospital visit: FEV1 after physiotherapy; oxygen saturation at rest; and exercise capacity and oxygen saturation on exercise. The type of exercise (treadmill, cycle, step or shuttle walk) varied between centres according to patient age and available equipment. Within centres, however, a consistent exercise protocol was used to measure total work achieved and oxygen saturation at a fixed level of exercise.
Symptom scores. Patients were asked to identify an exercise task which would make them breathless and to repeat this each day. During the second week of each 14-day period, symptom scores for dyspnoea during this task and for cough were recorded daily by patients on a diary card using visual analogue scales.

Materials. Blinding was achieved by overlabelling of ampoules containing $2.5 \mathrm{~mL}$ of DNase (Roche, Welwyn Garden City, Herts, UK) or $2.5 \mathrm{~mL}$ of $0.9 \%$ saline (Baker Norton, Harlow, Essex, UK; used as placebo). Placebo and DNase ampoules were similar in appearance. Aerosol treatment was given via a CR50 compressor and a Sidestream PZ nebulizer (System 22, Medic Aid, Pagham, Surrey, UK). Patients received the first dose of each medication under supervision and were asked to take subsequent doses once daily, midway between physiotherapy sessions. If patients required intravenous antibiotics for pulmonary exacerbations during an assessment, the assessment was scrapped and repeated at a later date.

\section{Analysis}

This was performed in two stages: 1) the entire data set was examined to determine how each parameter changed following placebo and DNase, in order to derive a score which quantified the response to DNase; and 2) the scoring system was used to classify each individual assessment as showing a response to treatment or not. If individuals showed a response in two or more assessments this individual was classified as a "responder" to DNase.

\section{Derivation of scoring system from entire data set}

The number of assessments in which a particular magnitude of change was seen after DNase or saline was determined first. For example, for FEV1 the number of assessments with an increase of $>0.2 \mathrm{~L}$ after DNase (over both baseline and post-saline measurements) was compared with the number of assessments with an increase of $>0.2 \mathrm{~L}$ after saline (over both baseline and post-DNase

Table 1. - Results of 89 assessments in 52 patients

\begin{tabular}{|c|c|c|c|c|c|}
\hline Parameter & $\begin{array}{l}\text { Magnitude of } \\
\text { change }\end{array}$ & $\begin{array}{c}\text { After DNase } \\
\text { (over both baseline } \\
\text { and saline) }\end{array}$ & $\begin{array}{c}\text { After saline } \\
\text { (over both baseline } \\
\text { and DNase) }\end{array}$ & $\begin{array}{l}\text { DNase/saline } \\
\text { ratio }\end{array}$ & $\begin{array}{l}\text { Score (adjusted for } \\
\text { correlations) }\end{array}$ \\
\hline \multirow[t]{2}{*}{ FEV1 (use in adults) L } & $\geq 0.15$ & 41 & 5 & 8.2 & 8.2 \\
\hline & $\geq 0.2$ & 33 & 3 & 11 & 11 \\
\hline FEV1 (use in children) $\%$ change & $\geq 10$ & 43 & 3 & 14.3 & 14 \\
\hline Resting $\mathrm{O}_{2}$ saturation $\%$ & $\geq 1$ & 30 & 11 & 2.7 & 2.3 \\
\hline Exercise $\mathrm{O}_{2}$ saturation $\%$ & $\geq 1$ & 36 & 15 & 2.4 & 2.1 \\
\hline \multirow[t]{2}{*}{ Work $\%$ change in work done } & $>5$ & 22 & 11 & 2 & 2 \\
\hline & $>10$ & 14 & 5 & 2.8 & 2.8 \\
\hline \multicolumn{6}{|l|}{ Symptoms } \\
\hline Shortness of breath & & $55^{*}$ & $34^{+}$ & 1.6 & 1.4 \\
\hline Cough & & $55^{*}$ & $34^{+}$ & 1.6 & 1.4 \\
\hline
\end{tabular}

For each parameter, the number of assessments is shown in which a given magnitude of change was seen. For example, for forced expiratory volume in one second (FEV1), an increase of at least $0.15 \mathrm{~L}$ was seen after deoxyribonuclease (DNase) (over both baseline and postsaline values) in 41 assessments, whereas after saline, only five assessments showed an increase of this size (over both baseline and post-DNase values). The ratio of these figures was used as the score for each parameter. Where changes in one parameter correlated with changes in another, the scores were correspondingly reduced (see text for further details). *: scored better after DNase than saline; ${ }^{+}$: scored better after saline than DNase. 
measurements). This process was repeated for each variable and scores were derived by taking the ratio of DNase to saline numbers (table 1). Symptoms were scored by measuring the patients' visual analogue scale diaries for the second week of each 14-day treatment period. Nonparametric correlation was used to determine which variables moved together and which had independent predictive power. Where measurements were correlated with each other the scores were adjusted down by $\mathrm{r}^{2} \%$ to allow for the variability which was common to both measurements.

\section{Results}

Data from 89 assessments in 52 patients ( 21 males) were collected from seven centres. There were 27 adults, with a
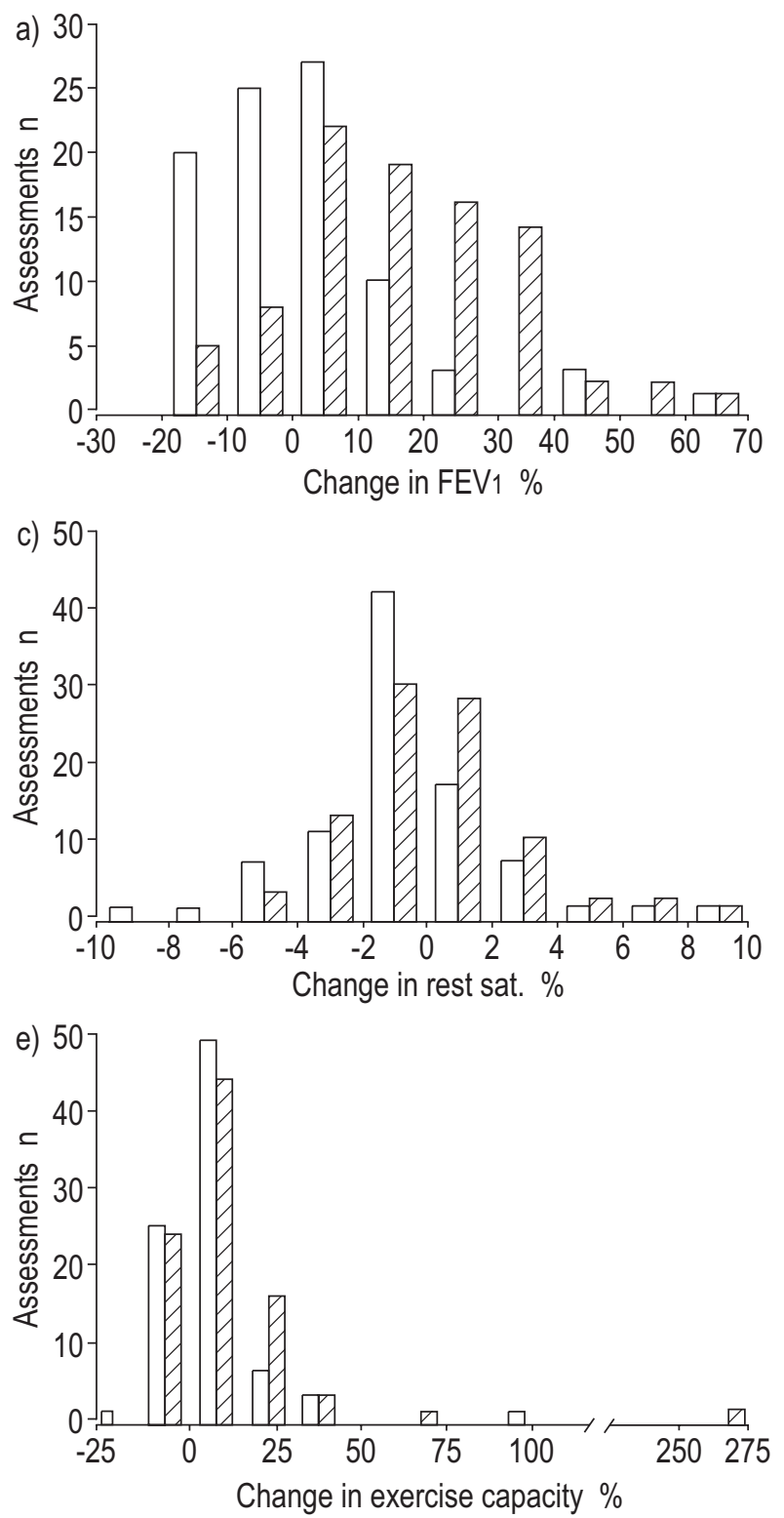

mean age of 26 yrs (range 17-47), a mean FEV1 of $1.69 \mathrm{~L}$ (45\% pred) and a mean FVC of $2.8 \mathrm{~L}(63.8 \%$ pred). The 25 children had a mean age of 12 yrs (range 8-16), a mean FEV1 of $1.31 \mathrm{~L}(55.4 \%$ pred) and a mean FVC of $2.19 \mathrm{~L}$ (81.7\% pred).

\section{Derivation of scoring system from group data}

Figure 1 illustrates the magnitude of changes seen after DNase (hatched bars). For FEV1 there is a significant ( $\mathrm{p}<$ 0.01 , paired t-test) shift of the hatched bars to the right, demonstrating a response to DNase. Oxygen saturation at rest and after exercise and work performed were also significantly improved after DNase compared with placebo $(p<0.05$, paired t-test or Wilcoxon rank sum test as

b) 40

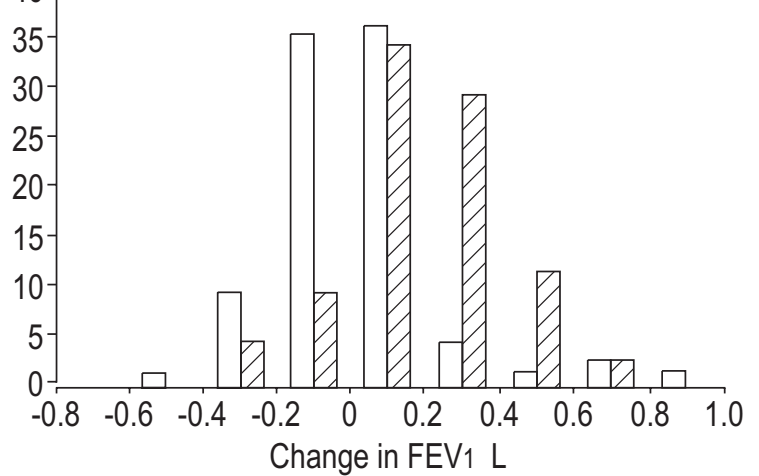

d) 35
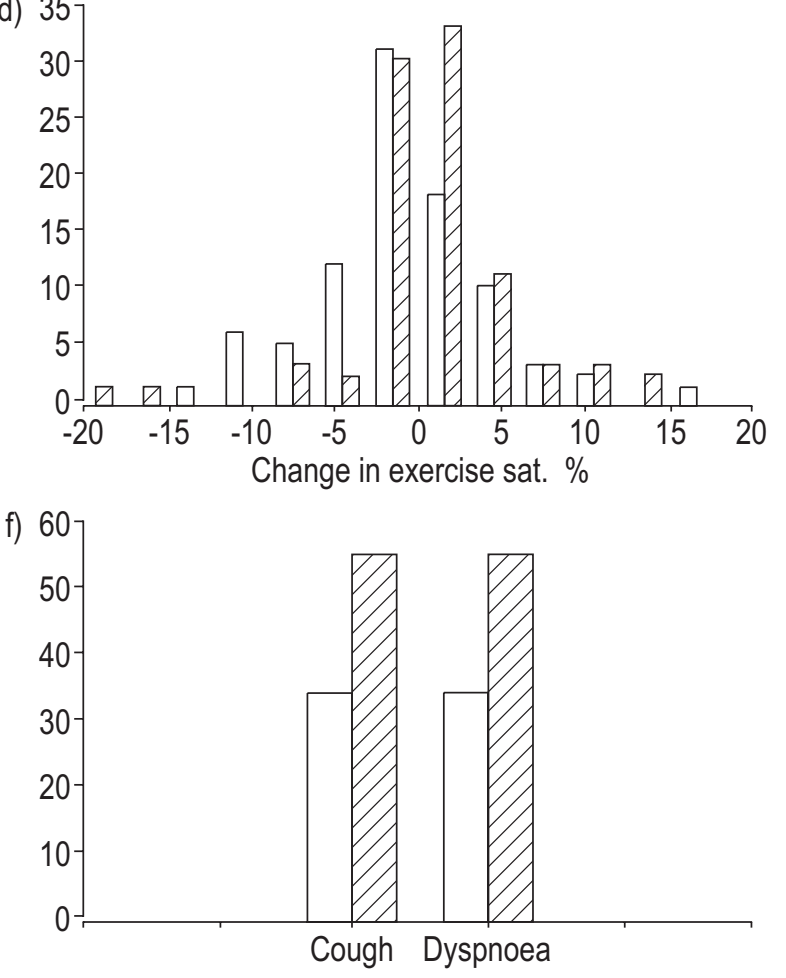

Fig. 1. - Changes in measurements and symptoms after deoxyribonuclease (DNase; $\square$ ) and placebo ( $\square$ ). In (a) to (e), bars show the number of assessment periods in which a given change (compared to baseline) was observed. Placebo responses, as expected, are centred around zero change. A beneficial effect of DNase is shown by a shift of the hatched bars to the right. f) Number of assessments in which patients scored their symptoms better during DNase than during placebo treatment $(\square)$ and the number in which they scored better during placebo than DNase ( $\square$ ). FEV1: forced expiratory volume in one second; sat.: saturation. 


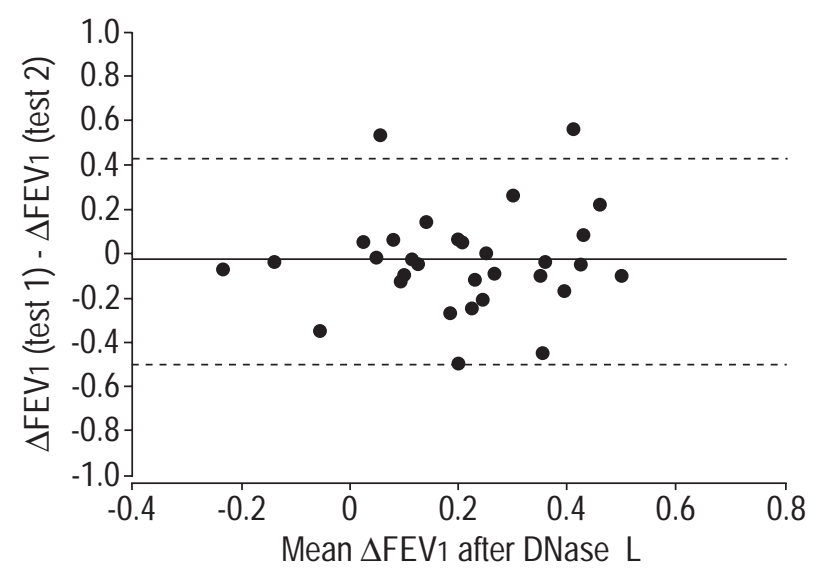

Fig. 2. - Bland and Altman plot of the reproducibility of the forced expiratory volume in one second (FEV1) changes in the 32 patients who had two assessment periods to compare. _— : mean difference between test 1 and test 2 responses; - - - : 95\% confidence interval for the difference between two successive responses. The mean difference is close to zero, but there is significant scatter which is unrelated to the magnitude of the FEV1 response. DNase: deoxyribonuclease.

appropriate), but the magnitude of the changes was smaller. Symptom score results showed significant improvements in cough and shortness of breath $(\mathrm{p}<0.05$ using significance tests for single proportions).

The reproducibility of FEV 1 responses in the 32 individuals who completed two assessments is shown in figure 2 . The mean difference between duplicate responses was $-0.03 \mathrm{~L}$ with a $95 \%$ confidence interval of $-0.50-0.42 \mathrm{~L}$.

Table 1 shows the results tabulated according to the number of times a given change was seen in a parameter following DNase compared with following placebo. The table also shows how these data were used to derive scores which attribute weight to different parameters according to how likely they were to change with DNase and placebo. Rank correlation revealed a few weak correlations between parameters: improvement in resting saturation correlated weakly with improvement in exercise saturation $(\mathrm{r}=0.36$, $\mathrm{p}<0.01$ ) and improvements in cough and breathlessness scores were correlated $(r=0.4, p<0.01)$. To allow for these correlations, the scores attributed to the partially correlated variables were reduced by $\mathrm{r}^{2} \%$ (table 1 ). Figure 3 shows an assessment score sheet illustrating how these scores may be used to generate an overall score indicating the magnitude of response in an individual to DNase. Absolute changes in FEV1 are appropriate for use in adults since the magnitude of change in FEV1 with treatment did not depend on the starting FEV1. However, in order not to disadvantage children (under $16 \mathrm{yrs}$ ), responses in this group were calculated as per cent changes (fig. 3 ).

\section{Defining a "response" to treatment}

Increasing scores indicate increasing magnitude of response to DNase, but what score indicates a significant response? A critical score to define a responder was derived by analysing all the placebo responses in patients who had undergone at least two 14-day placebo periods. This allowed us to ask the question "how often would a random (placebo) response generate, by chance, a given score appearing to be a positive response?" In 32 pairs of saline (placebo) assessments, the median score was 1.4 and the maximum score resulting from random variability between periods was 18.9. A score of $\geq 20$ was therefore chosen to define a response which was definitely beyond that expected by chance. Since none of the 32 pairs of measurements showed a score of $\geq 20$, the probability of such a score arising by chance (i.e. in the absence of a true drug effect) was estimated to be $<1$ in 32 i.e. $<0.03$.

\section{Application of scoring system to individual assessments}

Individual assessments were scored using a score sheet (fig. 3), which can be easily automated as a spreadsheet for convenience. At the time of writing, 52 patients have undergone 89 monthly assessments. Twenty-four patients have completed the whole assessment process, i.e. best of three 28-day assessments (12 overall responders, 12 overall nonresponders). Eight patients have yet to undergo a third assessment period (responded in one assessment period but not in the other) and 20 patients have completed one period to date ( 8 responders, 12 nonresponders). In 43 assessments the order of administration was DNaseplacebo and in 46 placebo-DNase; order had no detectable effect on results. There were 30 drop-out events (17 on saline), 27 due to infective exacerbations of CF.

The range of scores found during assessments is illustrated in figure 4 . This also shows the range of scores which occurred by chance when two sequential placebo (saline) assessments in an individual were scored in a similar way (see above). Scores of $\geq 20$ were only seen with active treatment, and there appears to be a bimodal response to DNase with many subjects not responding at all and some responding markedly (fig. 4).

\section{Discussion}

This blinded and controlled n-of- 1 trial approach has allowed the authors to define scores, based on clinically relevant measurements, which could detect and quantify a drug treatment effect within patients with a high degree of confidence, thereby facilitating appropriate targeting of treatment.

The advent of costly new therapies poses management dilemmas for clinicians seeking to use limited resources in the most beneficial way. Ideally treatment decisions for individuals are based on the results of double-blind randomized controlled trials, but frequently statistically significant mean results in large trials conceal wide individual variation in responses. In this situation, targeting therapy to maximum individual benefit can be difficult.

DAVIES et al. [13] carried out a retrospective review of the effects of DNase in 65 children with CF who were followed up at 1, 3, 5, 8 and 12 months. Approximately $50 \%$ of children had an increase of $>10 \%$ in FEV 1 and in nearly one-third the rise was $>20 \%$. An early improvement at 3 months was a good predictive marker for long-term benefit [13]. The modest mean rise in FEV1 of 5.8\% after DNase in a large multicentre study by Fuchs et al. [10] may be interpreted as a general mandate to treat all symptomatic patients. However, it is clear that not every patient benefited in this trial, and treating all patients would have significant resource implications. RoBSON et al. [14] calculated the average cost of care for a CF outpatient as $£ 8,606$; medication accounted for $43 \%$ of this. The respective figures in the Netherlands in 1991 were $£ 10,908$ 


\begin{tabular}{|c|c|c|c|c|c|c|c|c|}
\hline & & Baseline & $\begin{array}{l}\text { After } \\
\text { saline }\end{array}$ & $\begin{array}{c}\text { After } \\
\text { DNase }\end{array}$ & & & Scoring system & Score \\
\hline $\begin{array}{l}\text { 1. FEV } 1 \text { in adults } \\
\text { (scored on absolute } \\
\text { changes) }\end{array}$ & $\begin{array}{l}\text { Enter FEV } 1 \text { after } \\
\text { physiotherapy, in } \\
\text { litres }\end{array}$ & & & & $\begin{array}{l}\text { (DNase - baseline) } \\
\mathrm{A}:\end{array}$ & $\begin{array}{l}\text { (DNase - saline) } \\
\mathrm{B}:\end{array}$ & $\begin{array}{l}\text { If } A \& B \geq 0.15 \text { score } 8.2 \\
\text { If } A \& B \geq 0.2 \text { score } 11 \\
\text { If } A \text { and } / \text { or } B<0.15 \text { score } 1\end{array}$ & \\
\hline $\begin{array}{l}\text { 1. FEV } 1 \text { in children } \\
\text { (under } 16, \text { scored on } \% \\
\text { changes) }\end{array}$ & $\begin{array}{l}\text { Enter FEV } 1 \text { after } \\
\text { physiotherapy, in } \\
\text { litres }\end{array}$ & & & & $\begin{array}{l}\text { (DNase - baseline) } \\
\times 100 / \text { baseline } \\
\text { A: }\end{array}$ & $\begin{array}{l}\text { (DNase - saline) } \\
\times 100 / \text { saline } \\
\text { B: }\end{array}$ & $\begin{array}{l}\text { If } A \& B \geq 10 \% \text { score } 14 \\
\text { If } A \& B \geq 15 \% \text { score } 17 \\
\text { If } A \& B \geq 20 \% \text { score } 22 \\
\text { If } A \text { and/or } B<10 \% \text { score } 1\end{array}$ & \\
\hline $\begin{array}{l}\text { 2. Resting oxygen } \\
\text { saturation }\end{array}$ & Enter saturation in \% & & & & $\begin{array}{l}\text { (DNase - baseline) } \\
\mathrm{A}:\end{array}$ & $\begin{array}{l}\text { (DNase - saline) } \\
\text { B: }\end{array}$ & $\begin{array}{l}\text { If } A \& B \geq 1 \% \text { score } 2.3 \\
\text { If } A \text { and } / \text { or } B<1 \% \text { score } 1\end{array}$ & \\
\hline $\begin{array}{l}\text { 3. Exercise oxygen } \\
\text { saturation }\end{array}$ & $\begin{array}{l}\text { Enter saturation at } \\
\text { highest common } \\
\text { workload in } \%\end{array}$ & & & & $\begin{array}{l}\text { (DNase - baseline) } \\
\mathrm{A}:\end{array}$ & $\begin{array}{l}\text { (DNase - saline) } \\
\text { B: }\end{array}$ & $\begin{array}{l}\text { If } A \& B \geq 1 \% \text { score } 2.1 \\
\text { If } A \text { and } / \text { or } B<1 \% \text { score } 1\end{array}$ & \\
\hline $\begin{array}{l}\text { 4. Total work done } \\
\text { during exercise test } \\
\text { (scored on \% changes) }\end{array}$ & $\begin{array}{l}\text { Units will depend on } \\
\text { work protocol used }\end{array}$ & & & & $\begin{array}{l}\text { (DNase - baseline) } \\
\times 100 / \text { baseline } \\
\text { A: }\end{array}$ & $\begin{array}{l}\text { (DNase - saline) } \\
\times 100 / \text { saline } \\
\text { B: }\end{array}$ & $\begin{array}{l}\text { If } A \& B \geq 5 \% \text { score } 2 \\
\text { If } A \& B \geq 10 \% \text { score } 2.8 \\
\text { If } A \text { and } / \text { or } B<5 \% \text { score } 1\end{array}$ & \\
\hline 5. Cough & $\begin{array}{l}\text { Enter mean score for } \\
\text { second week }\end{array}$ & & & & $\begin{array}{l}\text { Better after DNase? } \\
\text { Yes No }\end{array}$ & & $\begin{array}{l}\text { Better after DNase score } 1.4 \\
\text { Worse after DNase score } 1\end{array}$ & \\
\hline 6. Breathlessness & $\begin{array}{l}\text { Enter mean score for } \\
\text { second week }\end{array}$ & & & & $\begin{array}{l}\text { Better after DNase? } \\
\text { Yes No }\end{array}$ & & $\begin{array}{l}\text { Better after DNase score } 1.4 \\
\text { Worse after DNase score } 1\end{array}$ & \\
\hline
\end{tabular}

Fig. 3. - Score sheet derived from the data in table 1, designed for scoring patient responses. The total score provides a way of quantifying the response in an individual to deoxyribonuclease (DNase); scores of $\geq 20$ are unlikely to arise by chance or natural variability (see text for further details). To calculate total score, multiply forced expiratory volume in one second (FEV1) score $\times$ resting saturation score $\times$ exercise saturation score $\times$ work done score $\times$ cough score $\times$ breathlessness score 


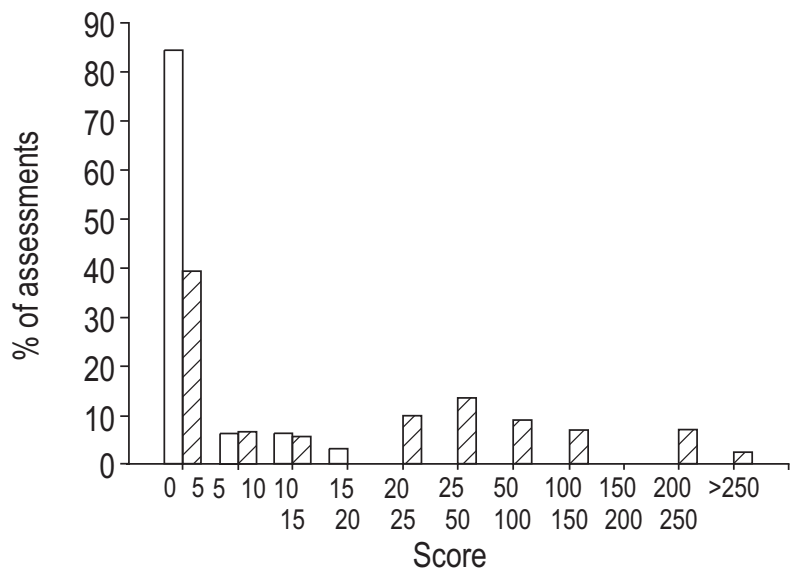

Fig. 4. - Frequency histogram of scores from assessments using active deoxyribonuclease (DNase; $\square$ ) and scores arising from clinical variability in patients over time (calculated by analysing sequential placebo (saline) responses in 32 pairs of assessments; $\square$ ). Scores $\geq 20$ are only found with active drug, and the response to active medication appears to be bimodal.

(medication 37\%) [15]. Once daily DNase in the UK costs $£ 7,442$ a year for each patient, i.e. treatment nearly doubles the cost of caring for an average UK CF patient. FUCHS and coworkers [16] analysed the effects of DNase on the cost of treating respiratory tract infections (RTI), and found a saving of US\$1,682 with once daily DNase compared with placebo, offsetting about one-third of the cost of such therapy.

Single patient trials (n-of-1) have been suggested as a solution to this common management dilemma. Teams at the University of Washington, Seattle [17] and McMaster University, Hamilton, Ontario [18] have reported their experience with formal n-of-1 services for clinicians, showing that $50-70 \%$ of completed studies gave a definitive result. Physicians' treatment decisions were influenced by the results in almost all cases and the majority of patients rated n-of- 1 trials as useful.

Assessment of individual DNase responses allows CF patients already on numerous medications not to be burdened with additional therapy if it is of marginal effectiveness in them. Furthermore, this type of assessment may help physicians to use the resources available for $\mathrm{CF}$ care in the most efficient and effective manner.

The n-of-1 protocol requires time and effort and becomes prolonged when patients have to withdraw from assessments with infective exacerbations. In this study, such infective complications were unrelated to whether or not the patient was receiving active medication. A minority of patients who might benefit from DNase are not stable enough to assess because they require antibiotics too frequently; for these the present protocol is inapplicable. The protocol of the present study was inevitably biased towards physiological and symptomatic measurements because they are the only ones which were practicable to include in an n-of-1 trial of acceptable brevity. More prolonged assessments would have greatly reduced compliance and increased drop-out due to intercurrent infections. No attempt was made to use the exacerbation rate as an end-point, although the study by FuCHs et al. [10] suggests exacerbations may be reduced over long periods by this drug. In an n-of- 1 trial, the random variability of exac- erbation interval within individuals makes this end-point impractical since extremely prolonged assessment would be necessary.

The study design incorporated the assumption that a responder will always remain a responder and vice versa. The variability of results within individuals over time (fig. 2 ) raises the question of whether patients should be retested after a period of time; this remains unanswered. FEV1 was the most sensitive discriminating parameter between DNase and placebo. Resting and exercise oxygen saturation and work capacity were less consistently influenced by DNase but revealed some predictive power. Weight did not change significantly after DNase in this study although SHAH et al. [11] reported in their open study a rise by $1.5 \mathrm{~kg}$ over a 2 yr period. Subjective symptoms dominate patients' views, and may be influenced by publicity surrounding the release of a new treatment. High expectations make subjective measures in unblinded assessments unreliable. High emotional investment can lead to patients attempting to unblind assessments (seen in at least one centre) to influence the outcome. However, it was found in this study that after suitable explanation the great majority of patients were willing to participate in the assessments and that their clinicians accepted the outcome.

Previous studies have shown significant improvements in wellbeing and some changes in CF-related symptoms (ease of sputum clearing, cough frequency and severity) and dyspnoea [8-10]. In the present study, assessments demonstrated significant improvements in cough and shortness of breath, but not (in the pilot protocol) in appetite, wellbeing and sputum clearing. The latter finding suggests that the majority of patients were not unblinding the assessment.

In conclusion, this multicentre n-of-1 assessment protocol provides one model of how expensive new therapies can be targeted to the patient group most likely to benefit.

Acknowledgements. The Scottish Cystic Fibrosis Group acknowledge gratefully the help of the following persons in the recruitment of patients, performance of assessments and recording and analysis of data: H.C. Rodgers, D.A. McArthur, V. Smith, K. Griffiths, C.A. Weller, P.S. Kilpatrick, T.J. Evans, and R. Muirhead. We also thank the staff in the pulmonary function laboratory of all centres, in particular J. Kilpatrick, C. King (Royal Hospital for Sick Children, Glasgow, UK); and J. Parkin, I. Yackiminie (Aberdeen Royal Infirmary, Aberdeen, UK).

\section{References}

1. Penketh ARL, Wise A, Mearns MB, Hodson ME, Batten JC. Cystic fibrosis in adolescents and adults. Thorax 1987; 42: 526-532.

2. Fitzsimmons SC. The changing epidemiology of cystic fibrosis. J Pediatr 1993; 122: 1-9.

3. Dodge JA, Morison S, Lewis PA, et al. Cystic fibrosis in the United Kingdom, 1968-1988: incidence, population and survival. Pediatr Perinatal Epidemiol 1993; 7: 157166.

4. Chernick WS, Barbero GJ. Composition of tracheobronchial secretions in cystic fibrosis of the pancreas and bronchiectasis. Pediatrics 1959; 24: 739-745.

5. Potter J, Matthews LW, Lemm J, Spector JS. Composition of pulmonary secretions from patients with and without cystic fibrosis. Am J Dis Child 1960; 100: 493-495. 
6. Lethem MI, James SL, Marriott C. The role of mucous glycoproteins in the rheologic properties of cystic fibrosis sputum. Am Rev Respir Dis 1990; 142: 1053-1058.

7. Shak S, Capon DJ, Hellmiss R, Marsters SA, Baker CL. Recombinant human DNase I reduces the viscosity of cystic fibrosis sputum. Proc Natl Acad Sci USA 1990; 87: 9188-9192.

8. Ramsey BW, Astley SJ, Aitken ML, et al. Efficacy and safety of short-term administration of aerosolized recombinant human deoxyribonuclease in patients with cystic fibrosis. Am Rev Respir Dis 1993; 148: 145-151.

9. Ranasinha C, Assoufi B, Christiansen D, et al. Efficacy and safety of short-term administration of aerolised recombinant human DNase I in adults with stable stage cystic fibrosis. Lancet 1993; 342: 199-202.

10. Fuchs HJ, Borowitz DS, Christiansen DH, et al. Effect of aerosolized recombinant human DNase on exacerbations of respiratory symptoms and pulmonary function in patients with cystic fibrosis. $N$ Engl J Med 1994; 331: 637-642.

11. Shah PL, Scott SF, Geddes DM, Hodson ME. Two years experience with recombinant human DNase I in the treatment of pulmonary disease in cystic fibrosis. Respir Med 1995; 89: 499-502.

12. Guyatt G, Sackett D, Taylor W, Chong J, Roberts R,
Pugsley S. Determining optimal therapy: randomized trials in individual patients. $N$ Engl $J$ Med 1986; 314: 889-892.

13. Davies J, Trindade M-T, Wallis C, Rosenthal M, Crawford O, Bush A. Retrospective review of the effects of DNase in children with cystic fibrosis. Pediatr Pulmonol 1997; 23: 243-248.

14. Robson M, Abbott J, Webb K, Dodd M, Walsworth-Bell J. A cost description of an adult CF unit and cost analyses of different categories of patients. Thorax 1992; 47: 684689.

15. Wildhagen MF, Verheij JBGM, Hilderink HBM, et al. Cost of care of patients with cystic fibrosis in The Netherlands in 1990-1. Thorax 1996; 51: 298-301.

16. Oster G, Huse DM, Lacey MJ, Regan MM, Fuchs HJ. Effects of recombinant human DNase therapy on healthcare use and costs in patients with cystic fibrosis. Ann Pharmacotherapy 1995; 29: 459-464.

17. Larson EB, Ellsworth AJ, Oas J. Randomized clinical trials in single patients during a 2 -year period. JAMA 1993; 270: 2708-2712.

18. Guyatt GH, Keller JL, Jaeschke R, Rosenbloom D, Adachi JD, Newhouse MT. The n-of-1 randomized controlled trial: clinical usefulness. Our three-year experience. Ann Intern Med 1990; 112: 293-299. 